\title{
Dry Type Brake Billiard plate Structure Thermoelastic Coupling Vibration Analysis
}

\author{
Yanzhong Wang ${ }^{1,}$, , Chao Guo ${ }^{1, b}$,Keyan Ning ${ }^{2}$ and Hai Lan ${ }^{2}$ \\ ${ }^{1}$ School of Mechanical Engineering and Automation, Beihang University, Beijing 100191, China \\ ${ }^{2}$ National Key Laboratory of Vehicle Transmission, China North Vehicle Research Institute, Beijing, \\ 100191, China \\ ayzwang63@126.com, ${ }^{\mathrm{b}}$ buaaguochao@163.com
}

Keywords: Thermoelastic, Vibration, Additional stiffness matrix, Dynamics analysis, Natural frequency

Abstract. This paper analyses the influence of the billiard plate stiffness by heat from the billiard plate dynamics equations and the brake temperature field distribution. Put forward the additional stiffness matrix calculation method through analysing the influence of elastic modulus by temperature and the influence of stiffness by thermal stress. Obtain the thermal vibration analysis results of billiard plate structure, under the influence of temperature and the pre-stressed. Calculation has been completed through the finite element and numerical iterative. This paper provides a meaningful reference for brake design.

\section{Introduction}

Working process is often accompanied by vibration for dry type brake. In the process of actual use, vehicle brakes often due to the high speed vehicle, braking frequently makes heating temperature rising sharply, which brings us difficulties to study the brake vibration characteristics. The main effect of temperature on the structure vibration characteristics embodied in two aspects: On the one hand reduces the elastic modulus of structure material; on the other hand, the uneven heat stress, eventually changes the structure stiffness characteristics. Billiard-plate Structure is loading device on dry type brake. The structure is shown in Fig. 1.

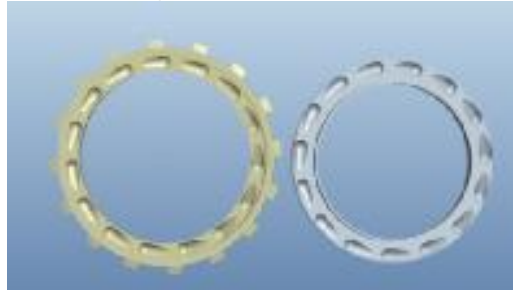

Figure 1 Structure of Billiard plate

The device through the ball and the ball groove convert rotary motion to linear motion, which can greatly increase the load pressure. Billiard-plate stability directly affects the stability of load pressure. Due to the high temperature, the thermal vibration effect needs further analysis. The brake structure diagram is shown in Fig. 2.

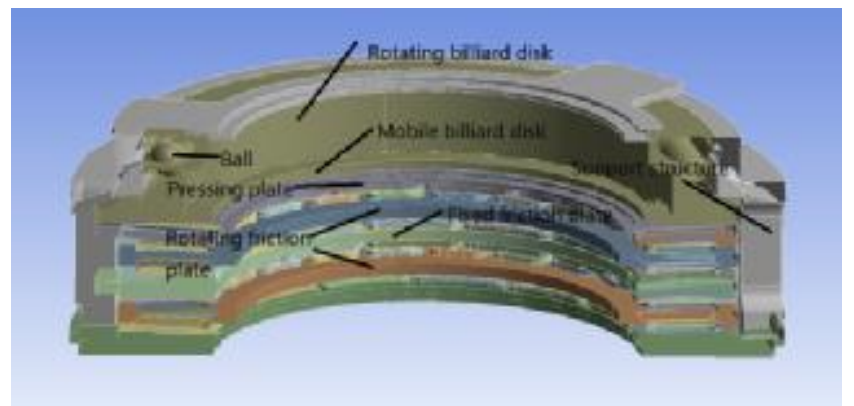

Figure 2 Brake structure

The thermal vibration is mostly focused on the rectangular plate achievements, for example, circular plate and elliptical plate on the establishment and solving the basic equations of thermal vibration. Equation established from the perspective of energy, using Hamilton principle or directly 
from the force balance to build. The researchers often adopt finite element method and finite difference method. Noor [1] and Reedy [2] has made a detailed review on static and linear thermoelastic analysis. Chang [3, 4] made a lot of work in thermoelastic coupling vibration of rectangular plates. Huang and Tauchert [5] analyzed on the angle of plates layer heated geometric nonlinear problem, but limited to the static. Chan [6] analyzed on the nonlinear static and dynamic response of the heated laminated plates, but based on the theory of mode 1. Kant [7] established thermal vibration model based on the theory of high mode. Spain, Soistmann and Linville [8] calculated two different materials of the shuttle's whole machine model under the condition of flight Mach number 6, aerodynamic heating effect on 5 modes natural frequency.

The influence of temperature on the vibration characteristics are implemented through influencing structural stiffness. Heating can weaken the structure stiffness from two aspects, one is reducing of the material elastic modulus, and the second is the stiffness change caused by the temperature gradient. Usually we adopt linear elastic theory analysis. Thermal stress as surface structure internal force will cause additional stiffness matrix (called the geometric stiffness matrix) change. When the thermal stress change is big, the additional stiffness matrix significantly changed the whole stiffness characteristics.

\section{The establishment of the billiard plate dynamics equation}

As shown in Fig. 3 is the billiard plate structure force analysis. The boll's radius is $R$. Rotating billiard plate subjected to force $\left(F_{1}\right)$. Mobile billiard plate's circumferential direction is constrained. The rolling friction are $f_{1}$ and $f_{2}$. Groove angle is $a$.

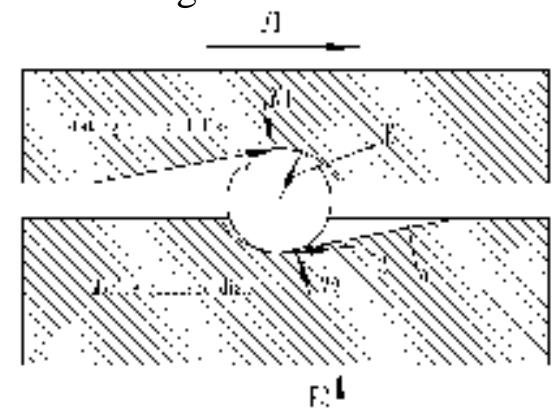

Figure 3 Billiard plate structure force analysis

Assuming that bolls do pure rolling motion billiard plate rotates. General dynamics relationship of billiard plate structure is shown in Fig. 4.

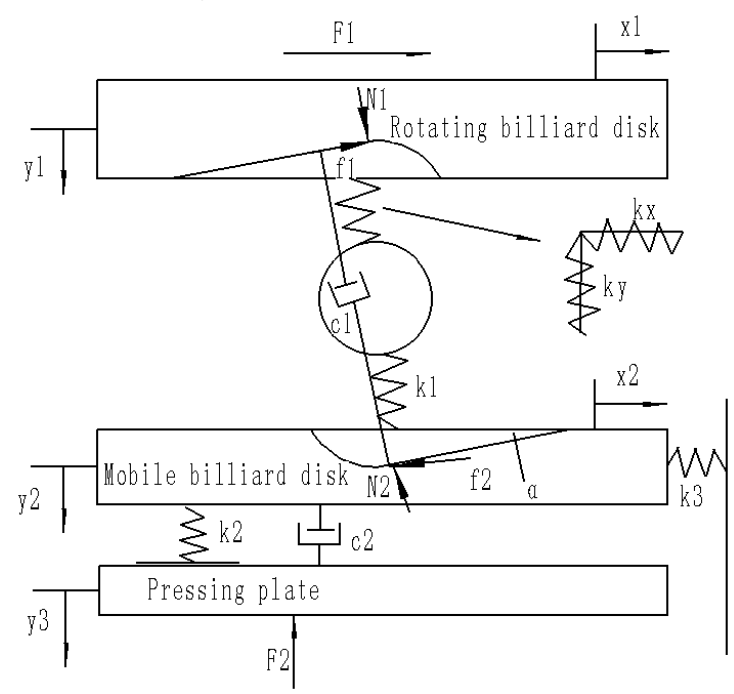

Figure 4 Billiard-plate dynamic model

The five degrees of freedom model is established. In fact $y_{1}$ freedom degree we don't focus on, if the support stiffness is sufficient. So actually four degrees of freedom system is established. According to the second class Lagrange's equation, the general form of the equation is: 


$$
\frac{d}{d t}\left(\frac{\partial T}{\partial \dot{Q}}\right)-\frac{\partial T}{\partial q_{j}}+\frac{\partial V}{\partial q_{j}}=Q_{j}^{*}
$$

Where $T$ is the kinetic energy of the system, $V$ is the potential energy of the system, $q_{\mathrm{j}}$ is generalized coordinates of the system, $\dot{q}_{j}$ is generalized velocity, $Q_{j}^{*}$ is generalized force of the system.

Ignoring the quality and the moment of inertia of the balls, kinetic energy and potential energy expression are as follows:

$$
\begin{aligned}
& T=\frac{1}{2} m_{1} x_{1}^{2}+\frac{1}{2} m_{1} y_{1}^{2}+\frac{1}{2}\left(m_{2}+m_{3}\right) x_{2}^{2}+\frac{1}{2} m_{2} y_{2}^{2}+\frac{1}{2} m_{3} y_{3}^{2} \\
& V=\frac{1}{2} k_{1}\left(x_{1}-x_{2}\right)^{2}\left(\frac{\tan a}{\cos a}\right)^{2}-\frac{1}{2} k_{1} \frac{\left(y_{2}-y_{1}\right)^{2}}{\cos ^{2} a}+\frac{1}{2} k_{2}\left(y_{2}-y_{3}\right)^{2}+\frac{1}{2} k_{3} x_{2}^{2}-g m_{1} y_{1}-g m_{2} y_{2}-g m_{3} y_{3}
\end{aligned}
$$

Due to the effect of constraint of the structure, it is assumed that stiffness of the supporting body enough. So the $y_{1}$ don't change. The generalized coordinates are:

$$
\left\{\begin{array}{c}
\frac{\partial V}{\partial x_{1}}=k_{1}\left(x_{1}-x_{2}\right)\left(\frac{\tan a}{\cos a}\right)^{2} \\
\frac{\partial V}{\partial x_{2}}=k_{1}\left(x_{2}-x_{1}\right)\left(\frac{\tan a}{\cos a}\right)^{2}+k_{3} x_{2} \\
\frac{\partial V}{\partial y_{2}}=\frac{k_{1} y_{2}}{\cos ^{2} a}+k_{2} y_{2}-k_{2} y_{3}-m_{2} g \\
\frac{\partial V}{\partial y_{3}}=k_{2} y_{2}+k_{2} y_{3}-m_{3} g
\end{array}\right.
$$

Generalized forces which corresponding to the generalized coordinates are:

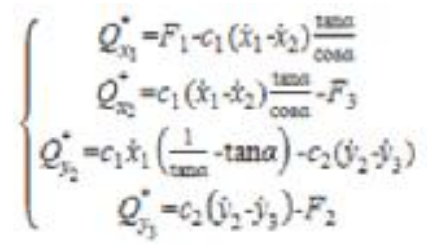

Then the matrix form of the dynamic differential equation is:

$$
\begin{aligned}
& {\left[\begin{array}{cccc}
m_{1} & 0 & 0 & 0 \\
0 & m_{2}+m_{3} & 0 & 0 \\
0 & 0 & m_{2} & 0 \\
0 & 0 & 0 & m_{3}
\end{array}\right]\left[\begin{array}{l}
y_{1} \\
x_{2} \\
y_{2} \\
y_{2} \\
y_{3}
\end{array}\right]} \\
& +\left[\begin{array}{cccc}
c_{1} \frac{\tan \alpha}{\cos \alpha} & c_{1} \frac{\cos \alpha}{\tan \alpha} & 0 & 0 \\
-c_{1} \frac{\tan \alpha}{\cos \alpha} & c \frac{1}{\cos \alpha} & 0 & 0 \\
-c_{1}\left(\frac{1}{\tan \alpha}-\tan \alpha\right) & 0 & c_{2} & -c_{2} \\
0 & 0 & -c_{2} & c_{2}
\end{array}\right] \\
& +\left[\begin{array}{cccc}
k_{1}\left(\frac{\tan \alpha}{\cos \alpha}\right)^{2} & -k\left(\frac{\tan \alpha}{\cos \alpha}\right)^{2} & 0 & 0 \\
-k_{1}\left(\frac{\tan \alpha}{\cos \alpha}\right)^{2} & k_{1}\left(\frac{\tan \alpha}{\cos \alpha}\right)^{2}+k_{3} & 0 & 0 \\
0 & 0 & \frac{k_{1}}{\cos ^{2} \alpha}+k_{2} & -k \\
y_{2} \\
y_{3}
\end{array}\right] \\
& 0
\end{aligned}
$$

Above model is based on the traditional dynamic analysis, which does not consider the heat effect on the stiffness. In addition the brake vibration process is usually under the compression state, so the influence of pre-stress on the system stiffness must be considered. Additional stiffness matrix calculation process is shown in Fig 5. 


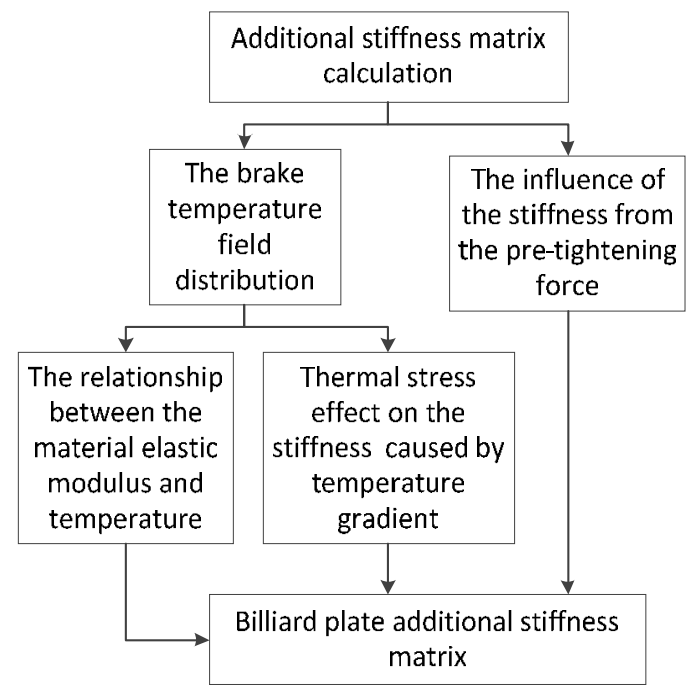

Figure 5 Additional stiffness matrix Calculation

Both temperature gradient generated by thermal stress and pre-tightening force generated by the pre-stress, there is no difference in nature. So in the paper we put the two aspects of influence together for discussion.

\section{The brake temperature field distribution and the impact analysis}

The brake thermal field is calculated with finite element method. Brake three-dimensional finite element model is established in this paper.

Table 1 Basic parameters

\begin{tabular}{cccc}
\hline Vehicle Quality(T) & Number of brake & $\begin{array}{c}\text { Number of friction } \\
\text { pair }\end{array}$ & $\begin{array}{c}\text { The friction pair area } \\
\left(\mathrm{m}^{2}\right)\end{array}$ \\
\hline 50 & 2 & 4 & $4.48 \times 10^{-2}$ \\
\hline
\end{tabular}

Through the analysis of vehicle operation condition complete the calculation of heat flux. Define the convective heat transfer coefficient to determine the heat flux distribution. We calculate the results of the brake temperature distribution under thermal fluid-solid coupling. The distribution of heat flux between the friction pair associates with convective heat transfer on the surface of the friction pair. Heat flow distribution coefficient not only related to the physical and chemical properties of materials, but also related to contact surface temperature gradient ratio. The table below is the material properties of friction materials.

Table 2 Material properties of Friction materials

\begin{tabular}{|c|c|c|c|c|c|c|}
\hline structure & Density & \multicolumn{2}{|c|}{ Specific heat capacity } & \multicolumn{3}{|c|}{$\begin{array}{l}\text { Coefficient of thermal } \\
\text { conductivity }\end{array}$} \\
\hline Rotating friction disk & 6700 & \multicolumn{2}{|c|}{452} & \multicolumn{3}{|c|}{. } \\
\hline Fixed friction disk & 7850 & \multicolumn{2}{|c|}{470} & \multicolumn{3}{|c|}{48} \\
\hline \multicolumn{7}{|c|}{$\begin{array}{l}\text { According to the working condition of the vehicle, the research got six different working } \\
\text { condition, temperature distribution under the different conditions are quite different, so the influence } \\
\text { of different working condition for billiard plate thermal vibration situation is different. } \\
\text { Table } 3 \text { Simulation Conditions }\end{array}$} \\
\hline Working Condition & 1 & 2 & 3 & 4 & 5 & 6 \\
\hline Braking acceleration $\left(\mathrm{m} / \mathrm{s}^{2}\right)$ & -5 & -4 & -2.5 & -4 & -2.5 & -5 \\
\hline Braking time(s) & 3 & 2.7 & 4.4 & 2.0 & 3.3 & 1.0 \\
\hline $\begin{array}{l}\text { Thermal power } \\
\left(\mathrm{W} \times 10^{5}\right)\end{array}$ & 4.2 & 2.5 & 1.5 & 1.9 & 1.2 & 1.8 \\
\hline $\begin{array}{l}\text { Heat flow density } \\
\qquad\left(\mathrm{w} / \mathrm{m}^{2} \times 10^{5}\right)\end{array}$ & 12 & 7.0 & 4.2 & 5.2 & 3.3 & 5.0 \\
\hline
\end{tabular}


According to the working condition of the above six through ANSYS-Workbench separately carried on the brake temperature field simulation analysis, the result is shown below.

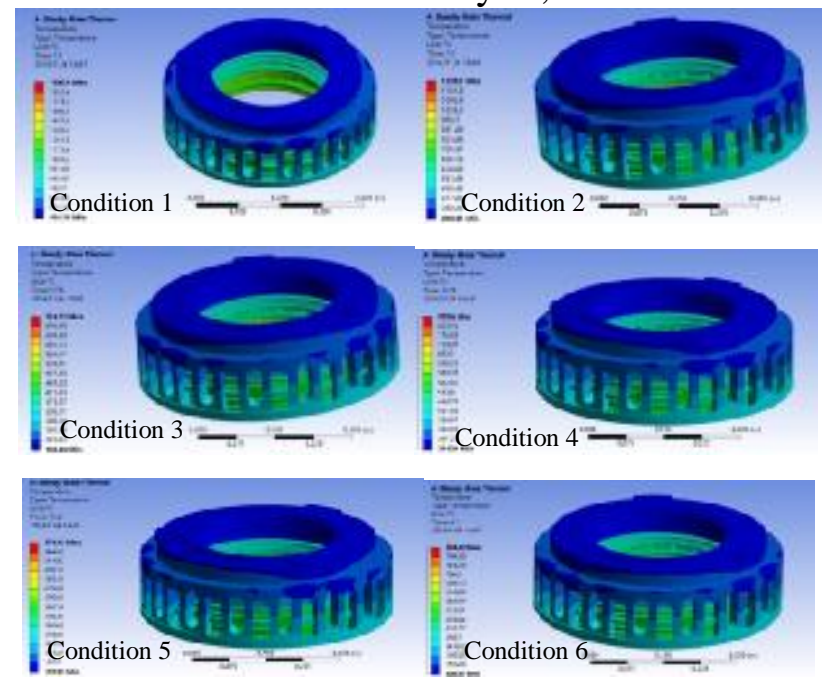

Figure 6 Calculation results of various kinds of working condition

Table 4 Maximum Thermal Stress of Billiard plate structure

\begin{tabular}{ccccccc}
\hline Working Condition & 1 & 2 & 3 & 4 & 5 & 6 \\
\hline $\begin{array}{c}\text { Max thermal } \\
\text { stress(MPa) }\end{array}$ & 21.78 & 13.34 & 8.16 & 10.49 & 6.35 & 1057 \\
\hline From the point of data of any of the above condition of simulation results, billiard plate structure
\end{tabular}

From the point of data of any of the above condition of simulation results, billiard plate structure temperature difference is big; billiard plate due to the structural constraint function at the same time, the thermal stress effect is obvious.

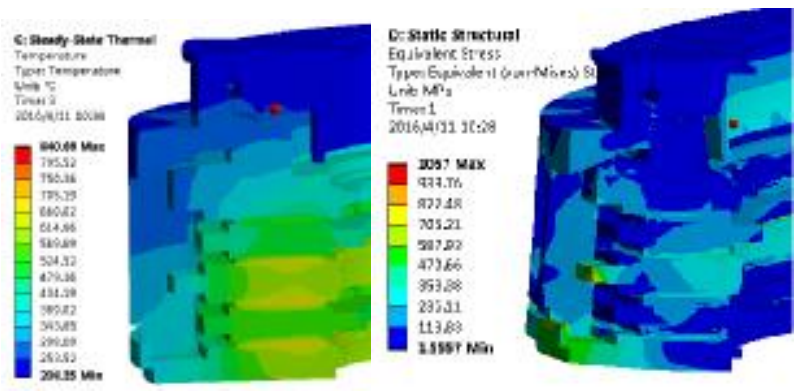

Figure 7 Temperature distribution and Structural Deformation Table 5 Maximum and Minimum temperature data

\begin{tabular}{ccccccc}
\hline \multirow{2}{*}{ structure } & \multicolumn{2}{c}{ Condition 1 } & \multicolumn{2}{c}{ Condition 2 } & \multicolumn{2}{c}{ Condition 3 } \\
& Max & Min & Max & Min & Max & Min \\
\hline Rotating Friction disc & 1390 & 1185 & 960 & 745 & 530 & 442 \\
Fixed friction disc & 1390 & 1275 & 960 & 835 & 530 & 482 \\
Pedestal & 1390 & 794 & 960 & 490 & 530 & 430 \\
Body Support & 794 & 416 & 490 & 282 & 350 & 208 \\
Billiard plate & 1390 & 416 & 960 & 282 & 530 & 208 \\
\hline \multicolumn{7}{c}{ Continue Table 5 } \\
\hline Condition 4 & Condition 5 & Condition 6 \\
\hline structure & Max & Min & Max & Min & Max & Min \\
\hline Rotating Friction disc & 650 & 530 & 430 & 302 & 650 & 542 \\
Fixed friction disc & 650 & 570 & 430 & 332 & 650 & 582 \\
Pedestal & 650 & 420 & 430 & 280 & 650 & 430 \\
Body Support & 430 & 214 & 280 & 157 & 430 & 208 \\
Billiard plate & 650 & 214 & 430 & 157 & 650 & 208 \\
\hline
\end{tabular}




\section{The relationship between the material elastic modulus and temperature}

Through the elastic modulus of metal materials with the temperature change of phenomenological explanation, can obtain the general relation between elastic modulus and temperature.

$$
\left\{\begin{array}{l}
\alpha=\frac{1}{r} \frac{d \eta}{d T} \\
\eta=-\frac{1}{r} \frac{d E}{d T}
\end{array}\right.
$$

Assume that heated expands atomic spacing follow the following pattern: $r=\mathrm{r}_{0}(1+\alpha \mathrm{T})$.

Where $\mathrm{r}_{0}$ is the atomic spacing when absolute temperature $\mathrm{T}_{0}=0, \alpha$ is linear expansion coefficient of material, $\eta$ is Temperature coefficient of modulus of elasticity $E$.

The formula shows that elastic modulus decreases with the rise of temperature in general situation of metal material. But whether in a straight line down it depends on the temperature coefficient of elasticity modulus $\eta$. The $\eta$ of metal material is hard to find, but the linear expansion coefficient $a$ experimental data is more fully. A number of studies have demonstrated that many ratios of linear expansion coefficient and temperature coefficient $\left(\alpha / \eta^{\alpha}\right)$ of metal and alloy material are close to a constant value.

So the general empirical formula of the elastic modulus with temperature changes is obtained.

$$
E=E_{0}(1-25 \alpha T) \quad(73.15<T<1073.15 \text {; }
$$

Where $\mathrm{E}_{0}$ metal elastic modulus under absolute temperature, $\mathrm{T} \mathrm{s}$ thermodynamic temperature scale. The formula are in good agreement under the $200^{\circ} \mathrm{C} \sim 800^{\circ} \mathrm{C}$ by experiment proof. It will meet the linear relationship basically. But deviation is larger when the environment temperature is higher than $800{ }^{\circ} \mathrm{C}$. The relationship between the elastic modulus and temperature of billiard plate materials is shown in the following table.

\begin{tabular}{|c|c|c|c|c|c|c|c|}
\hline & & \multicolumn{6}{|c|}{$\mathrm{E}^{*} 10^{10} \mathrm{~Pa}$} \\
\hline \multicolumn{2}{|c|}{$\mathrm{T}(\mathrm{K})$} & 288 & 773 & 823 & 873 & 923 & 973 \\
\hline $4 \mathrm{Cr}_{14}$ & test & 21.6 & 17.2 & 16.9 & 16.3 & 16.0 & 15.5 \\
\hline $\mathrm{Ni}_{14} \mathrm{~W}_{2}$ & calculate & 21.6 & 16.6 & 16.1 & 15.5 & 15.0 & 14.5 \\
\hline & test & 21.0 & 17.8 & 17.5 & 17.3 & 17.1 & 16.9 \\
\hline $38 \mathrm{CrSj}$ & calculate & 21.0 & 17.7 & 17.3 & 17.0 & 16.7 & 16.3 \\
\hline
\end{tabular}

Table 6 Relationship of $E$ and $T$

Analysis of system Stiffness and Stress relations

The internal stress referred to in this paper includes thermal stress and pre-stress which is generated by pre-tightening force. Studies have shown that natural frequency has close relationship with internal stress. As shown in Fig. 8 is the before four mode of system (Refers to the structured modal, does not contain the unstructured modal). Natural frequency produced obvious change, by adding different pre-stress. So the stiffness matrix produced a change in the system.

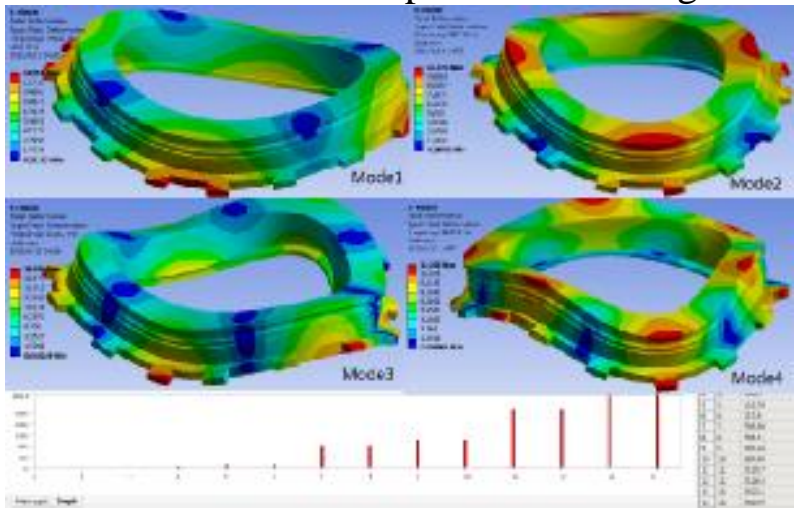

Figure 8 System Natural Frequency 
The additional stiffness matrix under the influence of thermal stress and pre-stress is obtained by solving the geometric stiffness matrix. Considering the billiard plate structure characteristics, the vibration strain is mainly composed of two parts: The first is strain because of billiard plate displacement change; the second is additional strain which produced by the deflection in the billiard plate because of the surface internal force. So suppose billiard plate material is isotropic, so additional strain energy is:

$$
\Delta U=\frac{1}{2}[\delta]^{\top}\left[K_{g}\right][\delta]=[\delta][Q]_{T}[\delta][Q]_{F}+C
$$

Where $[Q]_{1}=\int[B]^{T}[E]^{\top}[]_{T} d V$ is the equivalent load produced by the thermal stress of the system, $[B]=[\varepsilon] /[\delta],[Q]_{F}=\int[B]^{T}[E]^{2}[\varepsilon]_{F} d V$ is equivalent load produced by pre-stress, ${ }^{C=\frac{1}{2}} \int[\delta] F[E]_{T}[\theta]_{F} d V$ is only related to temperature $[E]_{,}[\delta]_{,}[\varepsilon]_{F},[\varepsilon]_{F}\left[K_{\ell}\right]$ are elastic modulus matrix, Unit displacement matrix, thermal strain matrix, pre-strain matrix and additional stiffness matrix respectively.

\section{Results Analysis of the Thermal Vibration}

Billiard plate dynamics equation is nonlinear dynamic equation. Use the classic 4 stairs variable step Runge - Kutta numerical integration method to solve. Calculation parameters are shown in table 7.

Table 7 Calculation parameters of Dynamic systems

\begin{tabular}{cc}
\hline Parameters & Numerical Value \\
\hline Rotating billiard plate $m_{1}$ & $40 \mathrm{~kg}$ \\
Mobile billiard plate $m_{2}$ & $40 \mathrm{~kg}$ \\
Pressing plate $m_{3}$ & $60 \mathrm{~kg}$ \\
Groove Angle & $20^{\circ}$ \\
Circumferential force $F_{1}$ & $10000 \mathrm{~N}$ \\
Axial force $F_{2}$ & $30000 \mathrm{~N}$ \\
Stiffness coefficient $K_{1}$ & $8^{*} 10^{6} \mathrm{~N} / \mathrm{m}$ \\
Stiffness coefficient $K_{2}$ & $5^{*} 10^{6} \mathrm{~N} / \mathrm{m}$ \\
Stiffness coefficient $K_{3}$ & $5^{*} 10^{6} \mathrm{~N} / \mathrm{m}$ \\
damping ratio $\xi_{1}$ & 0.016 \\
damping ratio $\zeta_{2}$ & 0.016 \\
\hline
\end{tabular}

Through calculation, the displacement and velocity curve of components are obtained, under $800^{\circ} \mathrm{C}, 50000 \mathrm{~N}$ pre-tightening force. The calculation results are shown in Fig.9. It is shown the additional stiffness matrix's influence of the displacement response of the $\mathrm{X}$ direction and $\mathrm{Y}$ direction. Its force is exerted at linear way. Linear function time is $0.1 \mathrm{~s}$. After of that, the force maintains a constant.

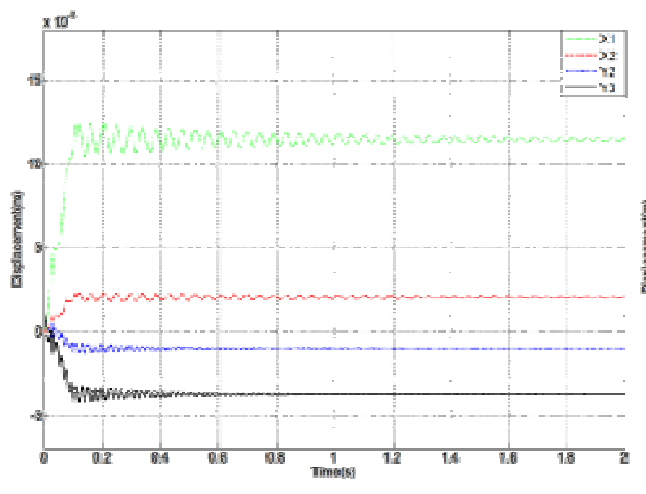

a

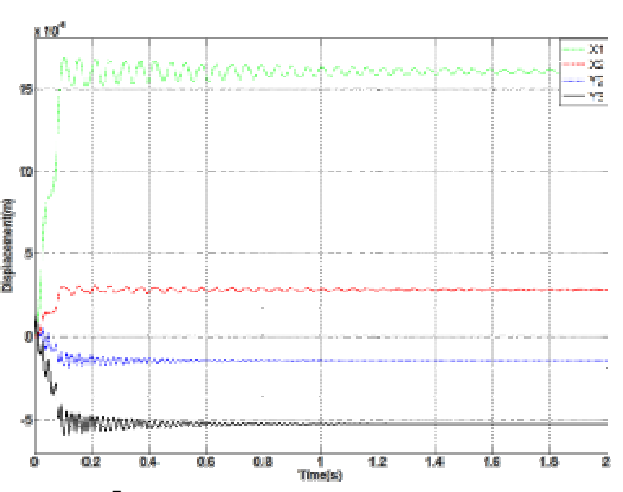

b

Figure 9 Different directions Displacement curve

the normal temperature condition for(a) and (b) $800^{\circ} \mathrm{C}$ high temperature state

After adding the additional stiffness matrix, Displacements of mobile billiard plate and rotating billiard plate are obvious changed. As the temperature increase stiffness decreases and the displacement increases. But there is no obvious change on amplitude. Stiffness weakening makes the 
speed increases obviously in loading process; and makes the velocity attenuation speed up. Stiffness significantly affect the vibration cycle. Smaller stiffness makes smaller vibration frequency.

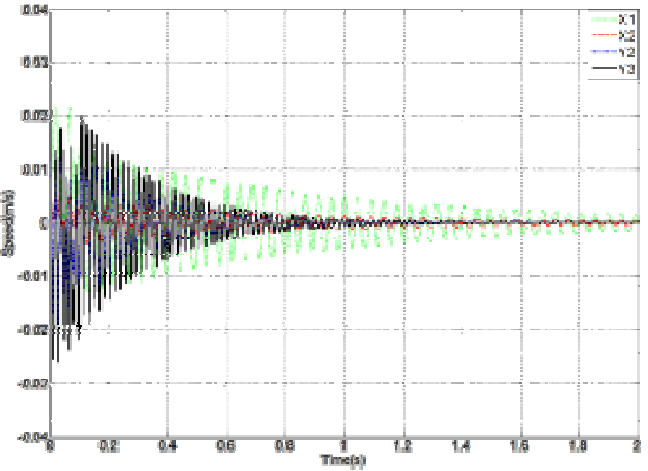

a

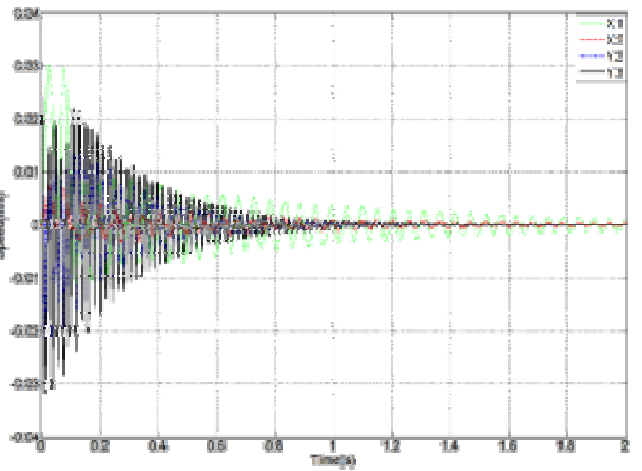

b

Figure 10 Different directions Speed curve

the normal temperature condition for(a) and (b) $800^{\circ} \mathrm{C}$ high temperature state

Through the system natural frequency solved, obtain the change of the natural frequency of the billiard plate under different working conditions. They are natural frequency curves of the billiard plate under different temperatures and the pre-tightening forces drawn in Fig 11. Natural frequency decreases with temperature increasing. And high modes are more sensitive to this effect.
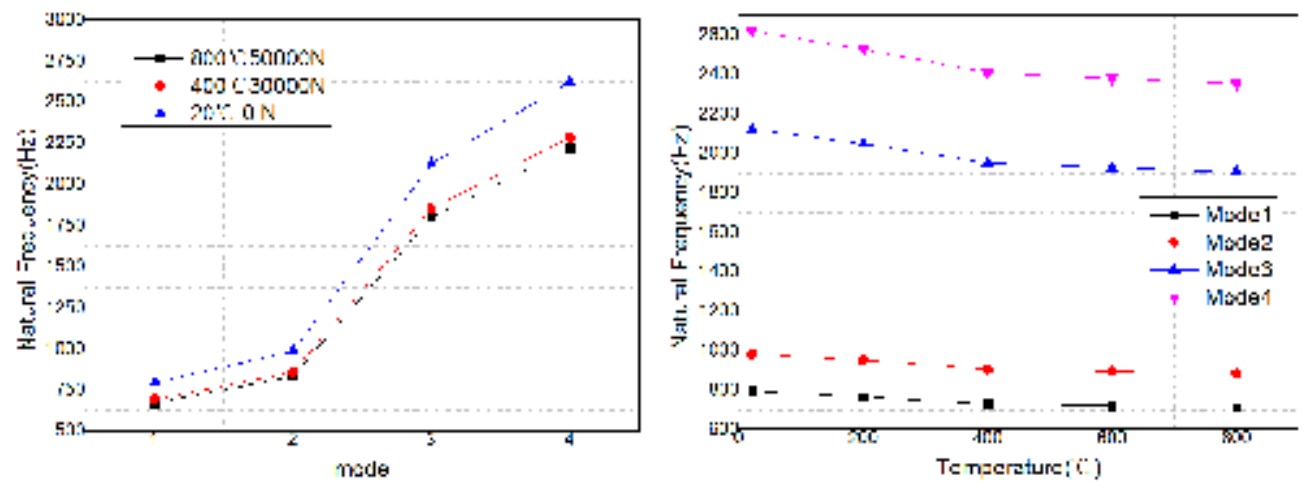

Figure 11 Natural Frequency curves

The influence degree of temperature is different for different modes seen in Fig.11. The effect of friction heat on system natural frequency has reached $19.1 \%$. The higher the temperature, the stronger the impact.

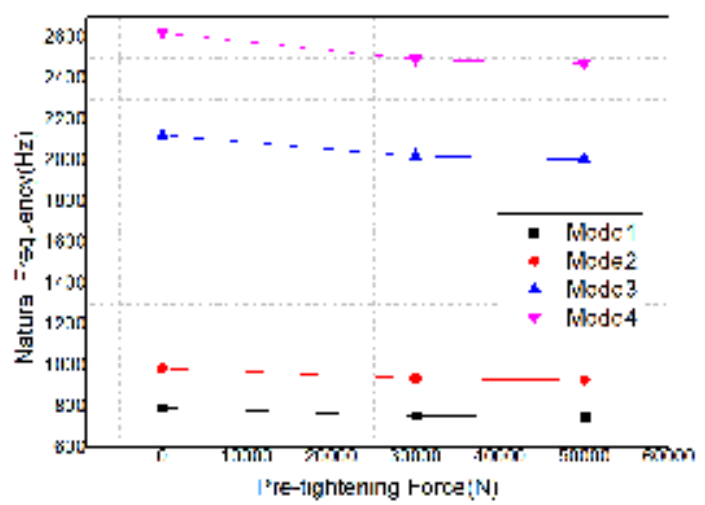

Figure 12 Effect of the Pre-stress

We contrast the maximum thermal stress with the stress produced by pre-tightening force, the temperature effect transform into force effect thereby. Fig.12 shows the effect of the pre-stress. It is found that with load increasing, the system natural frequency decreases. Natural frequency of the system change is not a linear change. For high pre-stress, the system frequency increment gradually smaller.

Fig.13 shows natural frequency change under the first two modes. Different modes show the same change rule. The effect of temperature on vibration is integrity. The effect is applicable for all the natural frequencies of the system. 


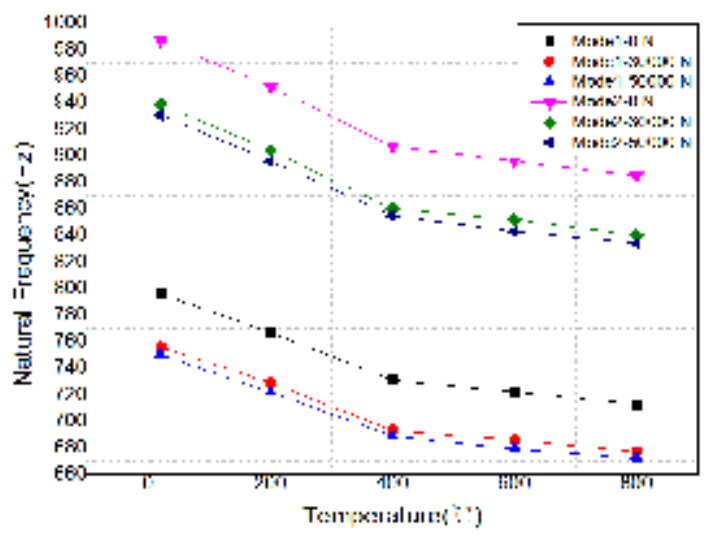

Figure 13 Influence of the first two modes

The effect of pre-stress on system natural frequency has reached $11.2 \%$. The stress produced by friction heat and the stress produced by force are no difference in essence.

\section{Conclusion}

In the research we mainly analyze the loading structure of dry type brake (Billiard plate) vibration characteristics under the influence of high temperature, and obtained some conclusions:

1. The main factors of structure stiffness change by high temperature are: the elastic modulus and internal stress.

2. Displacements of system are obvious changed. As the temperature increasing, stiffness decreases and the displacement increases. It makes the speed increases obviously in loading process; and makes the velocity attenuation speed up. Vibration frequency becomes smaller.

3. Temperature effects on system natural frequency are: as the temperature increasing, natural frequency decreases with the nonlinear changes.

\section{Acknowledgment}

This research was supported by a National Natural Science Foundation of China (Grant Number: $51275020)$.

\section{References}

[1] Noor A.K. and Burton C.W, Computational models for high-temperature multilayered composite Plates and shells, Appl.Med.ReV, 45 (10) (1992).

[2] Reddy.J. and Nand Chandrashakhara.K, Recent advances in the nonlinear Analysis flaminated composite plates and shells, Shoek and Vibration Dig. 19 (4) (1987).

[3] Chang W.P. and Wan S.M, Thermo mechanically coupled nonlinear vibration of Plates, Int. Journal. of Nonlinear mech, 21(5) (1986) 375-389.

[4] Chang W.P. and Jen S.C, Nonlinear free vibration of heated orthotropic rectangular plate, Int. Journal of Solid Structures, 22 (3) (1986) 267-281.

[5] Huang N.N. and Tauchert T.R, Large deformation fantasy metric angle-Ply laminates resulting from non-uniform temperature loading, Journal Thermal Stresses, (11) 1988 287-297.

[6] Chan drashak hara K. and Tenneti R, Nonlinear static and dynamic analysis of heated laminated Plates: A finite element approach. Compos. Sei.Tech, 51 (1994) 85-94.

[7] Kant, Tand and Kommineni J. R, Geometrically nonlinear transient analysis of laminated composite and sand-wich shells with are fried theory and $\mathrm{C} 0$ finite element, Computer struct, 52 (6) (1994).

[8] Spain C. V, Soistmann L. D. and Linville T. W, Integration of thermal effeets into finite element aerothermoelastic analysis with Illustrative results, Sixth National Aerospace Plane Technology Symposium, No.9 (1989). 